\title{
Antibiotic Prescribing Practices of Endodontic Postgraduate Trainees in Karachi, Pakistan
}

\author{
Azam Muhammad Aliuddin ${ }^{1}$ \\ BDS \\ Sarosh Sadruddin Morani ${ }^{2}$ \\ BDS \\ Abubakar Sheikh ${ }^{3}$ \\ BDS, FCPS \\ Saqib Rashid ${ }^{4}$ \\ BDS, MSc FCPS \\ Mohammad Ali ${ }^{5}$ \\ BDS, MCPS \\ Faryal Abdullah ${ }^{6}$ \\ BDS, DCPS
}

OBJECTIVE: The aim of this study was to assess the knowledge of Endodontic Postgraduate trainees regarding clinically relevant situations where an antibiotic cover is needed and is focused on the prescription patterns of various antibiotics depending on the clinical evaluation of the patients.

METHODOLOGY: A cross sectional study was performed in which data was collected from five different dental institutes offering post-graduate residency in endodontics all over Karachi, Pakistan. Preferred antibiotic for odontogenic infections and the duration for the antibiotic coverage were evaluated amongst postgraduate clinicians. A total of 100 questionnaires were distributed out of which only 82 questionnaires came back with responses. The study was conducted for a period of one month from August 2018- September 2018. The data collected was analyzed by SPSS version 21.

RESULTS: A combination of amoxicillin with Clavulanic acid was the first choice of antibiotic in patients with no known allergies to penicillin (40.6\%), whereas erythromycin was the first choice of antibiotic in patients having allergic reactions to penicillin (39.3\%). The duration of treatment on average was 5 days. In clinical situations of irreversible pulpitis, with or without apical periodontitis, $74.3 \%$ and $67 \%$ of the respondents prescribed antibiotics. $78 \%$ of respondents have prescribed antibiotics in cases of necrotic pulp with acute apical periodontitis.

CONCLUSION: Our study concludes that antibiotic over prescription is very common amongst post graduate trainees and is contributing towards a larger issue of antibiotic resistance. Proper protocols of prescription should be followed by professionals and further refinement is required focusing on need, duration and choice of the antibiotic being used.

KEYWORDS: Antibiotics, Odontogenic infections, Endodontics, Microbial resistance

HOW TO CITE: Aliuddin AM, Morani SS, Sheikh A, Rashid S, Ali M, Abdullah F. Antibiotic prescribing practices of endodontic postgraduate trainees in Karachi, Pakistan. J Pak Dent Assoc 2021;30(3):183-188.

DOI: https://doi.org/10.25301/JPDA.303.183

Received: 11 April 2020, Accepted: 16 February 2021

\section{INTRODUCTION}

$\mathrm{A}$ ntimicrobials and analgesics are the most regularly used medicines by dental professionals. Since the discovery of Penicillin in $1928^{1}$, various novel

1. FCPS II, Resident, Department of Operative Dentistry, Fatima Jinnah Dental College, Karachi, Pakistan.

2. House Officer, Department of Operative Dentistry, Fatima Jinnah Dental College, Karachi, Pakistan.

3. Associate Professor, Head of The Department of Endodontics, Fatima Jinnah Dental College, Karachi, Pakistan.

4. Professor, Head of The Department of Operative Dentistry, Fatima Jinnah Dental College, Karachi, Pakistan.

5. Assistant Professor, Department of Operative Dentistry, Fatima Jinnah Dental College, Karachi, Pakistan.

6. Senior Registrar, Management and Medical Education, Health Care System Management, Fatima Jinnah Dental College, Karachi, Pakistan.

Corresponding author: "Dr. Azam Muhammad Aliuddin” < azamaliuddin@yahoo.com> antibiotics were unearthed. The colossal use of antibiotics in dental practice is majorly attributed to dental professionals resorting to a safer side (preventing infection from occurring) and patients anticipating antibiotic prescription.

Odontogenic infections are usually polymicrobial. ${ }^{2}$ However, only a few occasions demand antibiotic prescription in dentistry. Odontogenic infections that involve signs of systemic involvement (cellulitis, fever) necessitate antibiotics prescription. ${ }^{3}$ Regarding the microbial flora in primary endodontic infections, gram negative anaerobic rods are the preponderant culprits. ${ }^{4}$ On the contrary, bacterial isolates from the root canals with failed endodontic treatments are found to inhabit predominantly facultative anaerobic and gram positive bacteria. ${ }^{5}$ 
In a review regarding antibiotics in Endodontics, it was highlighted that in Europe amoxicillin was the predominant choice of antibiotic prescribed during endodontic treatments. ${ }^{6}$ Regarding the indiscriminate prescription of antibiotics by dental practitioners a research was conducted in India in 2012 , the survey revealed that in conditions wherein only operative intervention would be sufficient, $50 \%$ of Endodontists prescribed antibiotics. ${ }^{7}$ Another research regarding prescription of analgesics and antibiotics in Endodontic practice was published in Saudia Medical Journal in 2014. It highlighted that analgesics were prescribed by $92 \%$ of the dentists for pain management whereas $16 \%$ dentists chose antibiotics for severe odontogenic pain. ${ }^{8}$

The intent of this research was to highlight the oral conditions, where antibiotic prescription is a must and is focused specifically on Pakistani dentists receiving postgraduate training in Endodontics. Through this study we want to achieve a clear understanding of dental issues requiring operative intervention with or without antibiotic coverage to help combat the global issue of antibiotic resistance faced by all healthcare professionals. A clear understanding and knowledge of medicines required to combat odontogenic infections and other oral problems will eventually lead to avoidance of over prescription of antibiotics and truncate chances of antibiotic resistance in the bigger picture.

\section{METHODOLOGY}

A cross sectional survey was conducted in 5 reputable institutions offering post graduate training in Operative Dentistry. A specified questionnaire was designed to investigate the postgraduate trainees' pattern of antibiotic prescription. The enclosed questionnaire was piloted by our Endodontic supervisors. Their criticism in regards to lucidity of the questions and additional proposals were brought into consideration leading to further refinement in the questionnaire.

The study was conducted at Fatima Jinnah Dental College, Karachi, Pakistan in the Department of Operative Dentistry. After obtaining the esthical approval fom the institute (Oct-2016-OPR). The antibiotic prescription survey was distributed in five reputable institutions offering post graduate training in Endodontics. Representatives from diverse institutions were given a week's time to get the questionnaire filled by Endodontic post graduates trainees. The study lasted for a month starting from August 2018 till September 2018.

A sample size of 80 was calculated using WHO calculator keeping a 5\% margin of error and 95\% confidence interval from a target population of 100. Although 100 questionnaires were mailed only 82 responses were selected as being useful.

Post graduate trainees of five institutions doing their residency in Operative Dentistry were included in the study. All residents from First year to final year of residency were included. All incomplete questionnaires returned to us were excluded from the study.

Variables under consideration included the required duration of antibiotic coverage and the preferred antibiotic for odontogenic infections in patients with no allergies. Demographic factors were also brought into consideration in the survey along with the indications for prescription of systemic antibiotics in endodontic treatments. Participants were required to give details regarding their preferred antibiotic and an alternate drug of choice in case of penicillin allergies. Analysis of the data collected was done via Statistical Package for the Social Sciences 21 software.

\section{RESULTS}

Of the 100 questionnaires mailed, 88 were returned. A total of 6 were returned as undeliverable, and the others $(n=82)$ were found to be usable. Table 1 describes the demographics of all respondents. Male respondents (67\%) were nearly double as compared to the female respondents

Table 1: Description of respondents $(n=82)$

\begin{tabular}{|l|c|c|}
\hline \multirow{2}{*}{ GENDER } & MALE & $55(67 \%)$ \\
\cline { 2 - 3 } & FEMALE & $27(33 \%)$ \\
\hline \multirow{3}{*}{ AGE GROUP } & $25-30$ years & $38(46 \%)$ \\
\cline { 2 - 3 } & $30-35$ years & $26(32 \%)$ \\
\cline { 2 - 3 } & $35-40$ years & $18(22 \%)$ \\
\hline MEAN AGE (year \pm SD) & $31.3 \pm 3.9$ & \\
\hline
\end{tabular}

(33\%). The highest percentage of respondents (46\%) was within the age group of 25 to 30 years. Whereas, $32 \%$ and $22 \%$ of the respondents fell into the age categories of $30-35$ years and $36-40$ years, respectively. The mean age was calculated to $31.3 \pm 3.9$ years.

Post graduates from all five institutions agreed that a 5-day antibiotic course is the preferred duration of treatment for endodontic infections. Table 2 illustrates antibiotic

Table 2: Antibiotic preference in patients with no medical allergies

\begin{tabular}{|l|c|c|c|c|}
\hline \multirow{2}{*}{ ANTIBIOTIC } & \multirow{2}{*}{ DOSAGE } & \multicolumn{2}{|c|}{ DURATION (5 day course) } & \multirow{2}{*}{ FREQUENCY } \\
\cline { 2 - 4 } & & BD & TDS & \\
\hline \multirow{3}{*}{ Amoxicillin } & $250 \mathrm{mg}$ & 17 & 13 & $30(19.4 \%)$ \\
\cline { 2 - 5 } & $500 \mathrm{mg}$ & 12 & 8 & $20(12.9 \%)$ \\
\cline { 2 - 5 } & $1000 \mathrm{mg}$ & 2 & 0 & $2(1.3 \%)$ \\
\hline \multirow{3}{*}{$\begin{array}{l}\text { Amoxicillin /Clavulanic } \\
\text { acid }\end{array}$} & $250 / 125 \mathrm{mg}$ & 0 & 0 & $0(0 \%)$ \\
\cline { 2 - 5 } & $500 / 125 \mathrm{mg}$ & 34 & 29 & $63(40.6 \%)$ \\
\cline { 2 - 5 } & $875 / 125 \mathrm{mg}$ & 22 & 16 & $38(24.5 \%)$ \\
\hline \multirow{3}{*}{ Metronidazole } & $200 \mathrm{mg}$ & 0 & 0 & $0(0 \%)$ \\
\cline { 2 - 5 } & $400 \mathrm{mg}$ & 0 & 2 & $2(1.3 \%)$ \\
\hline Clindamycin & $150 \mathrm{mg}$ & 0 & 0 & $0(0 \%)$ \\
\cline { 2 - 5 } & $300 \mathrm{mg}$ & 0 & 0 & $0(0 \%)$ \\
\hline Azithromycin & $250 \mathrm{mg}$ & 0 & 0 & $0(0 \%)$ \\
\cline { 2 - 5 } & $500 \mathrm{mg}$ & 0 & 0 & $0(0 \%)$ \\
\hline & & $87(56.1 \%)$ & $68(43.9 \%)$ & $155(100 \%)$ \\
\hline
\end{tabular}


preference in patients with no medical allergies. Majority of the responders chose Amoxicillin in combination with Clavulanic acid $(65.1 \%)$. The second most predominant choice was Amoxicillin alone (33.6\% responders). Only a very small percentage $(1.3 \%)$ of dentists preferred Metronidazole as the first choice. None of the respondents chose Clindamycin or Azithromycin. Table 3 shows antibiotic preference in patients with medical allergies. The predominant choice was Erythromycin (42.3\%). Metronidazole and

Table 3: Antibiotic preference in patients with medical allergies

\begin{tabular}{|l|c|c|c|c|c|}
\hline \multirow{2}{*}{ ANTIBIOTIC } & \multirow{2}{*}{ DOSAGE } & \multicolumn{3}{|c|}{ DURATION (5 day course) } & \multirow{2}{*}{ FREQUENCY } \\
\cline { 2 - 6 } & & OD & BD & TDS & \\
\hline \multirow{3}{*}{ Azithromycin } & $250 \mathrm{mg}$ & 0 & 2 & 2 & $4(3.6 \%)$ \\
\cline { 2 - 6 } & $500 \mathrm{mg}$ & 8 & 5 & 1 & $14(12.5 \%)$ \\
\hline \multirow{3}{*}{ Metronidazole } & $200 \mathrm{mg}$ & 0 & 0 & 2 & $2(1.8 \%)$ \\
\cline { 2 - 6 } & $400 \mathrm{mg}$ & 0 & 15 & 2 & $17(15.1 \%)$ \\
\cline { 2 - 6 } & $500 \mathrm{mg}$ & 3 & 1 & 0 & $4(3.6 \%)$ \\
\hline Clindamycin & $150 \mathrm{mg}$ & 0 & 0 & 2 & $2(1.8 \%)$ \\
\cline { 2 - 6 } & $300 \mathrm{mg}$ & 0 & 12 & 7 & $19(16.9 \%)$ \\
\hline \multirow{3}{*}{ Erythromycin } & $250 \mathrm{mg}$ & 0 & 0 & 3 & $3(2.7 \%)$ \\
\cline { 2 - 6 } & $500 \mathrm{mg}$ & 2 & 25 & 17 & $44(39.3 \%)$ \\
\hline Lincomycin & $500 \mathrm{mg}$ & 0 & 3 & 0 & $3(2.7 \%)$ \\
\hline & & $13(11.6 \%)$ & $63(56.3 \%)$ & $36(32.1 \%)$ & $112(100 \%)$ \\
\hline
\end{tabular}

Clindamycin were considered the first choice of antibiotics by only 20.5 and 18.7 percent of the respondents, respectively. Following this is Azithromycin (16.1\%) and Lincomycin which is only considered by $2.7 \%$ of the respondents as a preferred antibiotic.

Table 4 depicts the percentage of dentists prescribing antibiotics in varying clinical scenarios. $67.0 \%$ and $74.3 \%$ of the respondents considered antibiotic prescription necessary in the first two clinical situations, respectively. Other than

Table4: Antibiotic preference in patients with medical allergies

\begin{tabular}{|l|c|c|}
\hline CLINICAL SITUATION & FREQUENCY & PERCENTAGE \\
\hline A. Irreversible pulpitis, mod/severe pre-op symptoms & 55 & $67.0 \%$ \\
\hline $\begin{array}{l}\text { B. Irreversible pulpitis with acute apical periodontitis, mod/severe } \\
\text { pre-op symptoms }\end{array}$ & 61 & $74.3 \%$ \\
\hline $\begin{array}{l}\text { C. Necrotic pulp with chronic apical periodontitis, no swelling, } \\
\text { no/mild pre-op symptoms }\end{array}$ & 48 & $58.5 \%$ \\
\hline $\begin{array}{l}\text { D. Necrotic pulp with acute apical periodontitis, no swelling, } \\
\text { mod/severe pre-op symptoms }\end{array}$ & 64 & $78.0 \%$ \\
\hline $\begin{array}{l}\text { E. Necrotic pulp with chronic apical periodontitis, sinus tract present, } \\
\text { no/mild pre-op symptoms }\end{array}$ & 69 & $84.1 \%$ \\
\hline $\begin{array}{l}\text { F. Necrotic pulp with acute apical periodontitis, swelling present, } \\
\text { mod/severe pre-op symptoms }\end{array}$ & 78 & $95.1 \%$ \\
\hline
\end{tabular}

the first two scenarios wherein the diagnosis is irreversible pulpitis, all other situations have the diagnosis of necrotic pulp in common. Around $58.5 \%$ of the respondents prescribed antibiotics in the case with necrotic pulp, chronic apical periodontitis, no swelling, and no other symptoms. Almost $78.0 \%$ of respondents prescribed antibiotics for necrotic pulp, acute apical periodontitis, and moderate/severe symptoms but no swelling. The fifth clinical situation is similar to the third one but with the addition of sinus tract. Approximately $84.1 \%$ dentists considered antibiotic prescription significant in this case. Lastly the majority of respondents $(95.1 \%)$ generally agreed upon antibiotic prescription for patients with necrotic pulp, acute apical periodontitis, swelling, and other moderate/severe symptoms.

\section{DISCUSSION}

Analyzing the prescription habits of antibiotics during treatment of endodontic infections was the primary intent of the research. We targeted dental professionals receiving postgraduate training in Endodontics for this purpose. Our instrument was an independent questionnaire, aimed at inferring the first choice of antibiotics for both allergic and non-allergic patients. Furthermore, dentists were also asked to select the scenarios wherein they would preferably prescribe antibiotics.

According to our survey, Amoxicillin along with Clavulanic acid (500/125 mg) was the most agreed upon prescription for non-allergic patients receiving endodontic treatments $(40.6 \%$ respondents). Nearly $65 \%$ of the respondents preferred the combination of Amoxicillin with Clavulanic acid whereas, $33.6 \%$ consider Amoxicillin as the primary choice for non-allergic patients. Similar results were observed in a survey conducted in Spain, wherein $59.7 \%$ of the respondents chose Amoxicillin in combination with Clavulanic acid as their first choice. ${ }^{9}$ Earlier in 2013, a research was conducted amongst general dental practitioners in Karachi which illustrated Amoxicillin alone as their first choice (43.3\%). However, a slightly lower percentage (34\%) believed in the association of Amoxicillin along with Clavulanic acid. ${ }^{10}$ On the contrary, a higher percentage of dental surgeons in Hyderabad, India recommended Amoxicillin 500mg along with Metronidazole 400mg for pulpal and periapical pathosis. ${ }^{11}$ Members of American Association of Endodontics ${ }^{12}$ and dental practitioners from Lithuania ${ }^{13}$ and other countries of Europe ${ }^{14,15}$ had a similar output that is, Amoxicillin being the principle antimicrobial.

Amoxicillin is a moderate spectrum beta-lactam antibiotic and is regarded as an ideal choice that one should prescribe for dental infections. ${ }^{16}$ Although, it is considered to be a superior choice in comparison to most of the antibiotics but it is defenseless against -lactamase producing bacteria. For this reason the function of Clavulanic acid cannot be disregarded and its combination with Amoxicillin is unequivocally superior then prescription of Amoxicillin alone. This combination drug therapy has the advantage of lower bacterial resistance, broader spectrum (staphylococcal bacteria) and improved pharmacokinetic properties. ${ }^{17,18}$

Another antibiotic combination, preferred by dental surgeons in other parts of the world was Metronidazole and Amoxicillin. In our survey, $1.3 \%$ of the respondents chose Metronidazole as the preferred antibiotic. According to one of the researches Metronidazole is prescribed in addition to 
Amoxicillin, only when the latter is not efficacious on its own. ${ }^{19}$ Investigations have shown that Metronidazole tends to be more potent against obligate anaerobes as compared to facultative anaerobes. However, it is completely inefficacious against aerobic microorganisms. Hence, it can only be used in combination therapy for treating odontogenic infections. ${ }^{6}$

Diverse results were obtained from institutions regarding the choice of antibiotics for patients with penicillin allergy. According to our survey, Erythromycin 500mg (39.3\%) was preferred antibiotic for allergic patients. In contrast, results from an earlier research involving general dental practitioners of Karachi highlighted Clindamycin $(30.30 \%)$ as the predominant choice followed by Cephalexin $(23.6 \%)$ and Erythromycin $(22.5 \%) .{ }^{10}$ Similar results were also observed in United States. ${ }^{3}$ Around $72 \%$ of the postgraduate Spanish dentists chose Clindamycin 300mg as the preferred antibiotic for allergic patients while the remaining preferred Azithromycin (28\%). ${ }^{9}$ In our study, $16.1 \%$ of the respondents selected Azithromycin-semi synthetic derivative of Erythromycin for patients with penicillin allergy. Clindamycin (Lincosamide) was another predominant choice by $18.7 \%$ respondents. It is a broad spectrum antibiotic with excellent bioavailability and having a considerable coverage against anaerobes and gram positive cocci. Studies have shown that Clindamycin should be the choice of antibiotic in penicillin allergic patients. ${ }^{20,21}$

Another important aspect in prescribing antibiotics is duration of prescription. All five institutions that we targeted in our survey generally agreed upon 5 days being the preferable treatment duration. Similar results were obtained in Hyderabad, India with the addition of only $2.31 \%$ of respondents claiming antibiotic prescription for 7 days. ${ }^{11} \mathrm{In}$ Europe, specifically Spain generally dentists claimed that $6.8 \pm 1.2$ days is the appropriate time duration for antibiotic treatment. ${ }^{9}$ Studies have shown that if the causative factor is dealt successfully, it takes only 3 to 7 days for endodontic infections to resolve. ${ }^{22,23}$

Diverse pulpal and periapical conditions are encountered in clinical set ups. We have divided these situations into seven categories in our survey in order to investigate the clinical conditions wherein most of the postgraduate Endodontists preferred to prescribe antibiotics. The first and second clinical scenarios had the diagnosis of irreversible pulpitis along with moderate/severe symptoms, with the later having an integrant of acute apical periodontitis. According to our survey, majority of clinicians generally believed that there is a need of antibiotic prescription in the first two clinical situations, $67 \%$ and $74.3 \%$ respectively. On the contrary, in a study conducted in Spain the observed results were totally opposite and for scenario 1 and 2, only
11.4 and 28.6 percent clinicians preferred prescribing antibiotics, respectively. ${ }^{24}$ Whitten's et al. research also had similar findings. ${ }^{25}$ Pulp vitality and absence of systemic involvement are clear indications that only removal of the cause will suffice. Hence, prescribing antibiotics in the above mentioned scenario is unbefitting. ${ }^{26}$

Patients having pulpal necrosis with chronic apical periodontitis and no symptoms constitute the 3rd clinical category. There is no need of antibiotic prescription in an otherwise healthy patient. ${ }^{27}$ However, still $58.5 \%$ of the clinicians chose prescribing antibiotics as an option. Comparable results were seen in few other studies conducted in United States. ${ }^{3}$ A survey carried out in Spain illustrated that most dentists (92\%) correctly chose not to prescribe antibiotics in this scenario. ${ }^{16}$

Necrotic pulp with Acute Apical Periodontitis along with moderate/severe pre-op symptoms and no swelling constitute the 4th category. $78 \%$ of respondents prescribed antibiotics in this scenario. Pulpal necrosis with asymptomatic apical periodontitis and sinus tract constitute the 5th clinical situation wherein $84.1 \%$ respondents chose to prescribe antibiotics. For the fourth scenario, Whitten et $\mathrm{al}^{25}$ and Yingling et $\mathrm{al}^{3}$ have also demonstrated a high percentage of dentists prescribing antibiotics that are $67.3 \%$ and $53.9 \%$, respectively. These results further highlight the issue of inappropriate antibiotic prescription, which is extensive and needs to be catered. Comparatively lower percentage of respondents (29.2\%) considered the use of antibiotics essential in the 5th scenario (Whitten et al). ${ }^{25}$ Symptomatic apical periodontitis, pulpal necrosis and presence of swelling (sixth case) necessitate effective debridement of the root canal system, prescription of analgesics and incision and drainage. ${ }^{28}$ Our survey illustrates quiet a large number of respondents who prefer treating this clinical situation with antibiotics $(95.1 \%)$. According to one school of thought, investigators anticipate the prescription of antibiotics absolutely correct in the situation. ${ }^{29}$ On the contrary, there are various surveys in literature that only place their emphasis on the concept that antibiotics should only be prescribed in case of systemic involvement or patient being immunocompromised.

To sum up, dentists should only resort to antibiotics in clinical conditions wherein the patients are immunocompromised or if there are clear signs of systemic involvement. In the first five cases only non-surgical root canal treatment and analgesics are adequate for treatment. Antibiotics cannot play a worthy role because of the inability to reach the infection site and analgesics are only adjunctive medications used to diminish the pain caused by the infection and inflammation. ${ }^{30}$

Few limitations if addressed could have given a clearer 
picture and a wider perspective of antibiotic prescription patterns. Firstly, increased sample size could have had more favorable impact. In our study we only targeted dentists receiving postgraduate training in Endodontics (from five institutions). However, comparing Endodontists with the general dentists and final year BDS students, in terms of antibiotic prescription could have given a deeper perspective of the overall problem. Moreover, in the clinical situations medical health status was not provided. Analysis of the results shall be done keeping in view the above mentioned limitations.

\section{CONCLUSION}

The highest rate of antibiotic prescription was noted in cases of necrotic pulp having severe symptoms and extra oral swelling (95.1\%), whereas cases having necrotic pulp, mild symptoms and associated sinus tract was the second highest condition $(84.1 \%)$. According to our study another clinical scenario having very high rates of antibiotic prescription $(74.3 \%)$ was irreversible pulpitis with moderate to severe symptoms. The most preferred combination of antibiotics was amoxicillin with Clavulanic acid for patients non-allergic to penicillin (40.6\%), and for patients allergic to penicillin, Erythromycin was most commonly prescribed (39.3\%).

\section{CONFLICT OF INTEREST}

None to declare

\section{REFERENCES}

1. Tan SY, Tatsumura Y. Alexander Fleming (1881-1955): Discoverer of penicillin. Singapore Med J. 2015;56:366-67.

https://doi.org/10.11622/smedj.2015105

2. Liu R, Memarzadeh K, Chang B, Zhang Y, Ma Z, Allaker RP, et al. Antibacterial effect of copper-bearing titanium alloy (Ti-Cu) against Streptococcus mutans and Porphyromonas gingivalis. Sci Rep. 2016;6 (Article number)29985

https://doi.org/10.1038/srep29985

3. Baudet A, Kichenbrand C, Pulcini C, Descroix V, Lesclous P, Thilly $\mathrm{N}$, et al. Antibiotic use and resistance: a nationwide questionnaire survey among French dentists. Eur J Clin Microbiol Infect Dis. 2020;39:1295-303.

https://doi.org/10.1007/s10096-020-03849-0

4. Duran-Pinedo AE, Frias-Lopez J. Beyond microbial community composition: functional activities of the oral microbiome in health and disease. Microbes Infect. 2015;17:505-16.

https://doi.org/10.1016/j.micinf.2015.03.014

5. Nóbrega LMM, Montagner F, Ribeiro AC, Mayer MAP, Gomes
BPFA. Molecular Identification of Cultivable Bacteria From Infected Root Canals Associated With Acute Apical Abscess. Braz Dent J. 2016;27:318-24.

https://doi.org/10.1590/0103-6440201600715

6. Worsley DJ, Marshman Z, Robinson PG, Jones K. Evaluation of the telephone and clinical NHS urgent dental service in Sheffield. Community Dent Health. 2016;33:9-14.

7. Goud S, Fernandes S, Nagesh L. Are we eliminating cures with antibiotic abuse? A study among dentists. Niger J Clin Pract. 2012;15:151-55.

https://doi.org/10.4103/1119-3077.97291

8. Al-Maslamani M, Moule A, Sedeqi F. Prescription pattern of antibiotic and analgesic in endodontic treatment in Kuwaiti population: A self-administered Survey. Saudi Endod J. 2014;4:128-134. https://doi.org/10.4103/1658-5984.138142

9. Tanwir F, Khan S. Antibiotic prescribing habits of dentists of major cities of Pakistan. J Pak Dent Assoc 2011; 20:160-3.

10. Ikram K, Ahmed A, Siddiqui HK, Maqbool S, Mushtaq S, Sohail M. Over prescription of antibiotics by Karachi dentists working in public and private sector. Pak Oral Dent J 2015;35:10-3.

11. Saadat S, Mohiuddin S, Qureshi A. Antibiotic prescription practice of dental practitioners. In a public sector institute of Karachi. J Dow Uni Health Sci 2013; 7: 54-58.

12. Alonso-Ezpeleta O, Martin-Jimenez M, Martin-Biedma B, LopezLopez J, Forner-Navarro L, Martin-Gonzalez J, et al. Use of antibiotics by spanish dentists receiving postgraduate training in endodontics. $\mathrm{J}$ Clin Exp Dent. 2018;10:0.e687-e695.

https://doi.org/10.4317/jced.54894

13. Kumar KP, Kaushik M, Kumar PU, Reddy MS, Prashar N. Antibiotic prescribing habits of dental surgeons in Hyderabad city, India, for pulpal and periapical pathologies: A survey. Adv Pharmacol Sci 2013;2013:537385.(Article ID). https://doi.org/10.1155/2013/537385

14. Germack M, Sedgley CM, Sabbah W, Whitten B. Antibiotic Use in 2016 by Members of the American Association of Endodontists: Report of a National Survey. J Endod. 2017;43:1615-622.

https://doi.org/10.1016/j.joen.2017.05.009

15. Skucaite N, Peciuliene V, Maneliene R, Maciulskiene V. Antibiotic prescription for the treatment of endodontic pathology: a survey among Lithuanian dentists. Medicina (Kaunas). 2010;46:806-13. https://doi.org/10.3390/medicina46120113

16. Mansour H, Feghali M, Saleh N, Zeitouny M. Knowledge, practice and attitudes regarding antibiotics use among Lebanese dentists. Pharm Pract (Granada). 2019;16:1272.(1-11)

https://doi.org/10.18549/PharmPract.2018.03.1272

17. Kaptan, R. F., Haznedaroglu, F., Basturk, F. B., \& Kayahan, M. B. (2013). Treatment approaches and antibiotic use for emergency 
Aliuddin AM/ Morani SS/ Sheikh A/

Rashid S/ Ali M/ Abdullah F

dental treatment in Turkey. Therapeutics and clinical risk management, 9:443-49.

https://doi.org/10.2147/TCRM.S52009

18. Iqbal A. The Attitudes of Dentists Towards the Prescription of Antibiotics During Endodontic Treatment in North of Saudi Arabia. J Clin Diagn Res. 2015;9:82-4. https://doi.org/10.7860/JCDR/2015/13718.5964

19. Mücke T, Dujka N, Ermer MA, Wolff K, Kesting M, Mitchell DA, et al. The value of early intraoral incisions in patients with perimandibular odontogenic maxillofacial abscesses. J CranioMaxillofacial Surgery. 2015;43:220-23.

https://doi.org/10.1016/j.jcms.2014.11.009

20. Martín-Jiménez M, Martín-Biedma B, López-López J, AlonsoEzpeleta O, Velasco-Ortega E, Jiménez-Sánchez MC, et al. Dental students' knowledge regarding the indications for antibiotics in the management of endodontic infections. Int Endod J. 2018;51:118-27. https://doi.org/10.1111/iej.12778

21. Löffler C, Böhmer F. The effect of interventions aiming to optimise the prescription of antibiotics in dental care-A systematic review. PLoS ONE. 2017;12:e188061.

https://doi.org/10.1371/journal.pone.0188061

22. Al Khabuli J, Koeash M, Shah A. Knowledge and Attitude of Northern Emirates Dental Practitioners towards Antibiotic Prescription and its Resistance. Int J Dent Oral Health. 2016;2:2(1-8). https://doi.org/10.16966/2378-7090.177

23. Reddy K. Evidence Based Medicine: A Paradigm for Clinical Practice. J Gandaki Med Coll Nepal. 2018;11:74-81. https://doi.org/10.3126/jgmcn.v11i02.22989

24. Peedikayil FC Antibiotics in Odontogenic Infections - An Update. J Antimicro .2016;2(117):2472-1212. https://doi.org/10.4172/2472-1212.1000117
Antibiotic prescribing practices of endodontic postgraduate trainees in Karachi, Pakistan

25. Suda KJ, Calip GS, Zhou J, Rowan S, Gross AE, Hershow RC, Perez RI, McGregor JC, Evans CT. Assessment of the Appropriateness of Antibiotic Prescriptions for Infection Prophylaxis Before Dental Procedures, 2011 to 2015. J Am Med Assoc. Netw Open. 2019;2:e193909. https://doi.org/10.1001/jamanetworkopen.2019.3909

26. AlRahabi M, Abuong Z. Antibiotic abuse during endodontic treatment in private dental centers. Saudi Med J. 2017;38:852-56. https://doi.org/10.15537/smj.2017.8.19373

27. Balakrishnan G, Natarajan B, Thangavelu K. Comparison of efficacy of amoxicillin versus ciprofloxacin in postsurgical management of transalveolar extraction. J Pharm Bioall Sci. 2017;9:187-190. https://doi.org/10.4103/jpbs.JPBS_162_17

28. Maslamani M, Sedeqi F. Antibiotic and Analgesic Prescription Patterns among Dentists or Management of Dental Pain and Infection during Endodontic Treatment. Med Princ Pract. 2018; 27:66-72. https://doi.org/10.1159/000486416

29. Segura-Egea JJ, Gould K, Sen BH, Jonasson P, Cotti E, Mazzoni A, et al. European Society of Endodontology position statement: the use of antibiotics in endodontics. Int Endod J. 2018;51:20-5. https://doi.org/10.1111/iej.12781

30. Segura-Egea JJ, Gould K, Sen BH, Jonasson P, Cotti E, Mazzoni A, et al. Antibiotics in Endodontics: a review. Int Endod J. 2017;50:116984.

https://doi.org/10.1111/iej.12741

31. Agnihotry A, Fedorowicz Z, van Zuuren EJ, Farman AG, AlLangawi JH. Antibiotic use for irreversible pulpitis. Cochrane Database of Systematic Reviews. 2016;2:49-69.

https://doi.org/10.1002/14651858.CD004969.pub4

32. Schuh CMAP, Benso B, Aguayo S. Potential Novel Strategies for the Treatment of Dental Pulp-Derived Pain: Pharmacological Approaches and Beyond. Front Pharmacol. 2019;10:68. https://doi.org/10.3389/fphar.2019.01068 